\title{
Biomedical Engineering Letters indexed in Science Citation Index Expanded (SCIE)
}

\author{
Jae Sung Lee ${ }^{1,2}$
}

Received: 23 November 2021 / Revised: 25 November 2021 / Accepted: 25 November 2021 / Published online: 15 December 2021

(c) Korean Society of Medical and Biological Engineering 2021

On behalf of the editorial team, as editor-in-chief, I am pleased to announce that Biomedical Engineering Letters has been newly included in Science Citation Index Expanded (SCIE) of Web of Science. Consequently, articles published from Volume 9 (2019) onward will be indexed in the Web of Science Core Collection. Further, the journal expects to receive its first Journal Impact Factor (JIF) in the June 2022 release of Journal Citation Reports (JCR).

Biomedical Engineering Letters was launched in 2011 as the official academic journal of the Korean Society of Medical and Biological Engineering (KOSOMBE), and has since steadily developed into a reputable international journal dealing with emerging topics in biomedical engineering and applied biophysics. Over the past 11 years, the journal's editorial team have made every effort to improve the quality of published articles and maintain high ethical standards throughout the publication process. In particular, we published special issues of the journal on various subjects to create collections of papers dedicated to specific areas of research with a broad appeal and within the aims and scope of Biomedical Engineering Letters. As a result, the journal has regularly been cited over the past several years. The journal was also added to SCOPUS, PubMedCentral, Emerging Sources Citation Index (ESCI) and many other abstract and citation databases.

The SCIE indexing is a significant milestone for the journal, and would not have been possible without the concerted efforts of many people. On behalf of the editorial team, I would like to thank all the authors, reviewers, and guest editors for their outstanding support and contribution. Moreover, I would like to express my deepest gratitude to the leaders and directors of KOSOMBE, including President Dongwook Kim, for their unwavering support. Many thanks also go to the advisory and editorial boards of Biomedical Engineering Letters as well as the editors and staff of Springer Nature. We look forward to the greater success of the journal with your continued collaboration.

With the recent indexing in SCIE, interest in Biomedical Engineering Letters along with the number of paper submissions is expected to increase significantly in the next few years. Accordingly, the editorial team commits to redouble its efforts to select only the best papers with meaningful contributions to the relevant research fields and to improve the quality of submissions accepted for appraisal. To this end, we will actively recruit promising editors and reviewers into our editorial board. Furthermore, we will prioritize professional publishing ethics over advancing the citation of articles and the visibility of the journal. We will continue to keep all processes of journal publication fair and transparent; our readers will be regularly updated via the journal website.

Publisher's Note Springer Nature remains neutral with regard to jurisdictional claims in published maps and institutional affiliations.

Jae Sung Lee

jaes@snu.ac.kr

1 Department of Nuclear Medicine, Seoul National University College of Medicine, 103 Daehak-ro, Jongno-gu, Seoul 03080, Korea

2 Interdisciplinary Program in Bioengineering, Seoul National University Graduate School, Seoul, Korea 